\title{
Fully automatic cleaning system of smart street lights: a new design via Alf and vegard's RISC processor
}

\author{
Morteza Hadipour $^{1}$. Javad Farrokhi Derakhshandeh ${ }^{2} \mathbb{D} \cdot$ Reza Rezaei $^{3}$
}

Received: 5 December 2019 / Accepted: 10 June 2020 / Published online: 15 June 2020

(c) Springer Nature Switzerland AG 2020

\begin{abstract}
In this study, a new design of a full automatic cleaning system known as FACS is manufactured and used for street lighting systems. FACS is derived and controlled with a microcontroller. The system consists of an auto turn On/Off control system for the light and passive infrared sensor to save energy. The dust/rain sensors are utilised to recognize the dirt/ drops accumulation and surface deposition on the surface of the lights. The proposed cleaning system is compared with all available technologies, and the pros and cons of the systems are described and compared in detail. The comparison reveals that for removing the dirt accumulation, a fully automatic cleaning system can be chosen as one of the most suitable cleaning systems due to its robustness, using for different types of street lights, excellent performance at a shorter time and low-cost. The evaluation of the total cost unveils that FACS is cheap and applicable system and it can be employed in industrial sector.
\end{abstract}

Keywords The automatic cleaning system · Street lighting control system $\cdot$ Real-time control $\cdot$ Smart city $\cdot$ AVR

$\begin{array}{ll}\text { Abbreviations } \\ \text { AC } & \text { Alternating current } \\ \text { Amp } & \text { Ampere } \\ \text { AVR } & \text { Alf and vegard's RISC processor } \\ \text { AWS } & \text { Automatic washing system } \\ \text { CW } & \text { Clockwise } \\ \text { CCW } & \text { Counter clockwise } \\ \text { dB } & \text { Decibel } \\ \text { DC } & \text { Direct current } \\ \text { FACS } & \text { Full automatic cleaning system } \\ \text { GPS } & \text { Global positioning system } \\ \text { GSM } & \text { Global system for mobile communications } \\ \text { GND } & \text { Ground } \\ \text { GPRS } & \text { General packet radio service } \\ \text { Hz } & \text { Hertz } \\ \text { IC } & \text { Integrated circuit } \\ \text { IP } & \text { Ingress protection code } \\ \text { loT } & \text { Internet of things }\end{array}$

$\begin{array}{ll}\text { LED } & \text { Light-emitting diode } \\ \text { NCS } & \text { Networked control system } \\ \text { PCB } & \text { Printed circuit board } \\ \text { PIR } & \text { Passive infrared sensor } \\ \text { PLC } & \text { Programmable logic controller } \\ \text { PLCs } & \text { Programmable logic controller system } \\ \text { R } & \text { Resistor } \\ \text { RPM } & \text { Revolutions per minute } \\ \text { SMD } & \text { Surface mounted device } \\ \text { SMS } & \text { Short message service } \\ \text { SCADA } & \text { Supervisory Control and data acquisition } \\ \text { V } & \text { Voltage } \\ \text { VAC } & \text { Voltage alternating current } \\ \text { VDC } & \text { Voltage direct current } \\ \text { W } & \text { Watt } \\ \text { 2D } & \text { Two-dimensional space } \\ \text { 3D } & \text { Three-dimensional space }\end{array}$

$\bowtie$ Javad Farrokhi Derakhshandeh, javad.farrokhi@aum.edu.kw; farrokhi.javad@yahoo.com | ${ }^{1}$ Department of Electrical Engineering, Hamedan Branch, Islamic Azad University, Hamedan, Iran. ${ }^{2}$ College of Engineering and Technology, American University of the Middle East, Kuwait City, Kuwait. ${ }^{3}$ Department of Electrical Engineering, Kermanshah Branch, Islamic Azad University, Kermanshah, Iran. 


\section{Introduction}

This study develops a new automatic cleaning system for street lights to increase the illumination of the lights. In the previous work, Hadipour et al. [1] innovated a new mechanism known as an automatic washing system (AWS) to remove the dirt accumulation from the surface of the street lights. This operation is automatically controlled using three relays, for controlling the motor of the cleaning system, for running the pump of the system and for the input power.

\subsection{Energy demand}

In the twenty first century, energy is an essential part of the economic activities. The global energy requirements increased by the years, as it is expected to rise more than $50 \%$ by 2030 [2]. However, with increasing cost of electricity and the impact of fossil fuels, the world is now tending to use more renewable energy sources such as solar $[3,4]$ wind energy $[5,6]$, ocean/river energy [7-9] and biomass and geothermal energy [10, 11]. This rapid demand is pushing electricity towards $20 \%$ and highlights the importance of electricity as it continues to place it as a clean and environmentally fuel for the near future [2].

Street light systems are mostly considered as the biggest or at least the second-biggest energy demand of energy in the developed cities [12].

It is evident that the distance between two road/ street lights is evaluated based on veiling luminance, which can be affected by other road criteria such as road cross-sections, intersection condition, traffic volume, the horizontal and vertical alignment of the road, operational and maintenance costs, and crime rate [13]. Based on all these criteria, the average standard distance of two poles can be approximately estimated between 30 and $50 \mathrm{~m}$. It is seen that tens of thousands of street lights easily should be employed throughout the entire a large and smart city or even between the cities; In contrast, the street/road lighting systems provide many essential benefits, these facilities are known as one of the largest electrical consumers with approximately $40 \%$ of the total energy consumption [14].

Having thousands of street lights and keeping them more efficient is a big challenge in smart cities, in particular with lots of dirt accumulation. Due to the dust, surface deposition, and dirt accumulation, the illumination of the street lights reduces up to $60 \%$ [15]. One solution is providing a regular cleaning of the street lights based on a predefined program to increase the illumination of the lights and the reduction of maintenance costs. The initial expenses of the electrical energy and the environmental factors encourage the authors to implement solutions to design and manufacture an intelligent mechanism for cleaning the surface of the street lights.

Conventional solutions for cleaning the surface of the street lights were limited to manual cleaning, industrial elevators, and climbing robots [16]. It has been shown that the manual cleaning method is a frustrating solution, especially in large cities, and causes some problems such as traffic congestion [1]. While the relatively new equipment, such as the industrial elevator or climbing robot, can eliminate the weakness of the manual cleaning system, these methods are still time-consuming, and most of them cause traffic congestion [2].

\subsection{Different washing systems}

In this section, the conventional and alternative cleaning systems/methods of the street lights are reviewed. Generally, the surface of the lights can be cleaned via four systems/methods: 1 . Industrial lifts; 2 . Folding lamp post; 3. Climbing robots [2]; 4. Automatic remote washing system. Figure 1 shows the different available cleaning systems of the street lights.

It is important noting that in the first three methods, as mentioned earlier, the human factor (operator) plays a significant role in the implementation of this operation. Due to this operation requirement, thus, these methods are time-consuming.

In industrial lift systems, the human resources are employed to wash the lights by a basket that caries the pump and water tank. Of these, the cost of an hourly car rental is proportional to the maximum height of lights and factors. While the advantage of this method is replacing broken bulbs and painting the tower of light and performing maintenance operations simultaneously with the washing process, the risks of injuries and road accidents are high.

In climbing robot systems, an equipped robot with an arm and a cleaner head and a water tank are mounted on the tower of the light with the assistance of at least two operators. By sending orders, the robot can elevate the tower and clean the surface of the luminance. The operation of the robot is highly dependent on weather conditions. Though, in this technology, the amount of water usage is reasonable (about $0.5-1 \mathrm{~L}$ ), the operation of cleaning is approximately long and takes 10-30 min.

In folding lamp post, due to the unique design of the pole, the operator can easily access to the low-level headlamp surface to carry out the task. This technology has its pose, such as high efficiency and performing cleaning 
Fig. 1 Different cleaning system of street lights; a Industrial lifts; b folding lamp post; c climbing robots [15]; d automatic remote washing system [1]
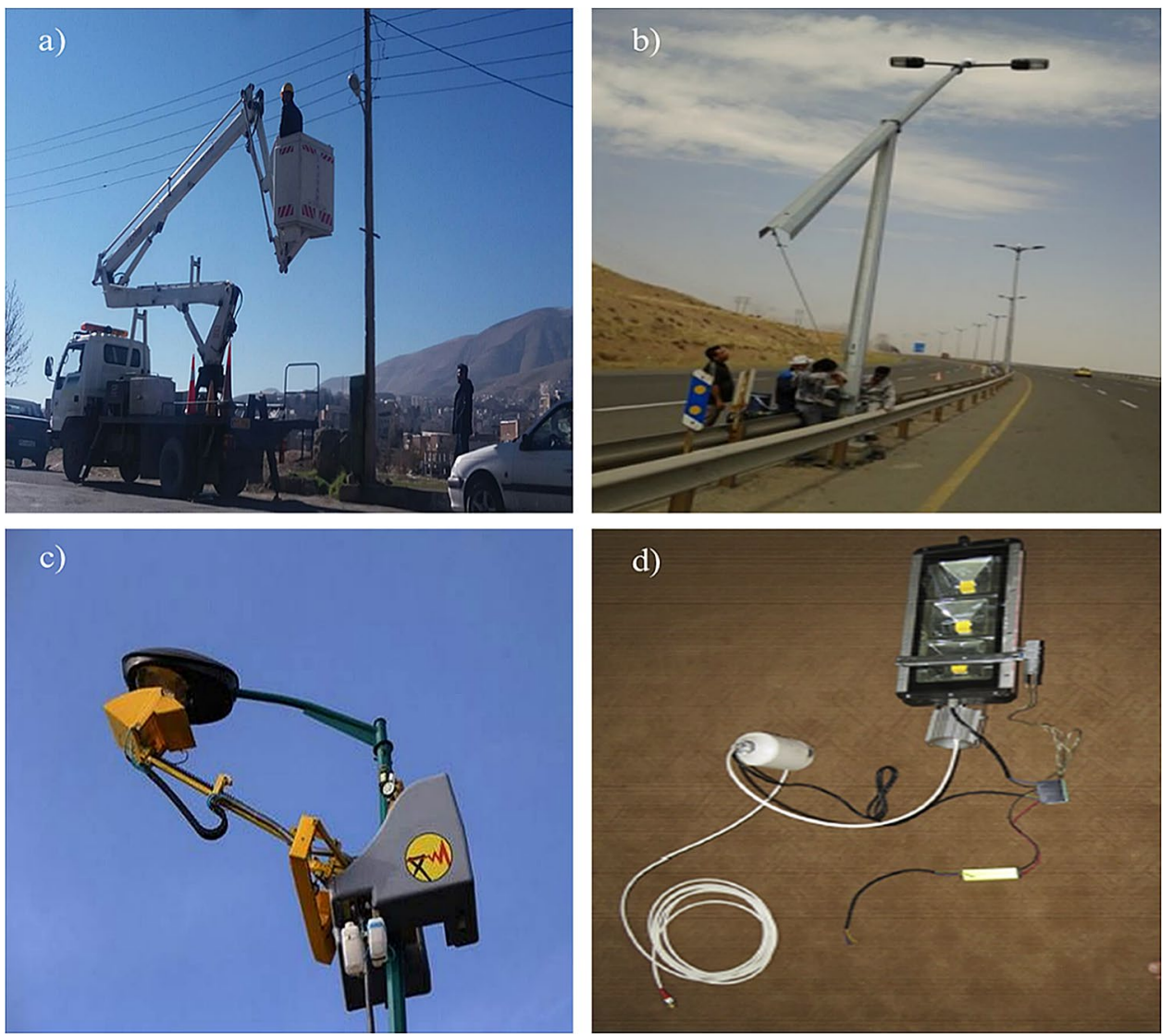

operation and other required maintenance activities simultaneously; however, the cost of installation is relatively high due to its unique design. Besides, this system cannot be installed in narrow streets. Besides, it is impossible to employ this system in concrete and wooden structures.

\subsection{Control systems}

Different control systems and technologies are now available in the industry, such as Programmable logic controller (PLC), Supervisory Control and Data Acquisition (SCADA), Networked Control System (NCS), and Arduino [17-20].

As compared with the Arduino system, it has been shown that PLCs are robust systems, and the system has a better processor power, and memory; though their costs are massive [24].

SCADA is, generally, proposed for collecting and managing data [20]. The total cost of the SCADA system is also high and can be suggested for the large industrial sector [21].

NCS control systems have been up-and-coming applications for a few decades. NCS is very popular and widely used in the industry. One of the primary capabilities of NCS is information acquisition, such as sensors, command (e.g., controllers), communication and network, and control, such as actuators [22]. NCS has been used for a long time; however, there are still challenging issues and unsolved problems to be considered for future investigations. With increasing real-life applications of NCS, the real-time secured control is vital. This condition gives rise to a real-time optimization problem and a security threat modelling requirement in NCS. Consequently, due to the large number of sensors, controllers, and actuators spatially distributed on a network, designing a fault-tolerant control system for a large-scale with NCS control system is still very difficult [22].

Arduino, on the other hand, is an open-source platform using for programing of electronics and consists of both a physical programmable circuit board (a microcontroller) and a piece of software [23]. Although the coding of the Arduino system is time-consuming, this feature (coding) increases the flexibility of the system with more creativity and innovation in project management. Programming Arduino microcontroller is not only very easy in terms of installation as compared with other control systems, but also the initial and maintenance costs of Arduino is low [24]. Therefore, it is reasonable to use this control system for a considerable number of applications such as street lights. Recently, the 
usage of the Arduino system is dramatically increasing due to the above advantages $[8,21,24]$.

The objective of this paper is to improve and optimize the primary mechanism and control system. The focus is to design a robust mechanism as compare to the AWS. Besides, the new proposed system is cost-effective and faster than the previous mechanism introduced by the authors [1].

The structure of this study is described here; in Sect. 1, a brief introduction related to the importance of energy sources is presented, which is followed by comparing the available mechanism for washing the street lights and description of the operating control system for cleaning systems. In Sect. 2, the mathematical model of the mechanism is presented. Section 3 describes the control system of the FACS in detail and introduces the mechanical and electrical features of the system. Finally, Sect. 4 will end up with the final comparison of the conventional and alternative cleaning systems.

\section{Mathematical modelling of the system}

FACS was designed based on the defined program to the Arduino micro-controller. The Electro-Mechanical system of FACS is shown in Fig. 2, including mechanical and electrical sections. The proposed control system is designed and programmed in Arduino-microcontroller to complete the link between mechanical and electrical sections. The mechatronic system, therefore, is composed of an actuator, which is a DC motor and its gearbox, the windshield wiper cleaning mechanism. The measurement system to run and activate the system are two sensors (rain and dust sensors) and the controller.

The mechanical and electrical differential equations according to Newton's and Kirchhoff's laws governing the dynamics can be written as follows, respectively:

$$
\begin{aligned}
& k_{i} i_{a}(t)-k_{d} \frac{d \theta}{d t}=J \frac{d^{2} \theta}{d t^{2}} \\
& R i_{a}(t)+L \frac{d i_{a}(t)}{d t}+V_{b}(t)=V_{s}(t)
\end{aligned}
$$

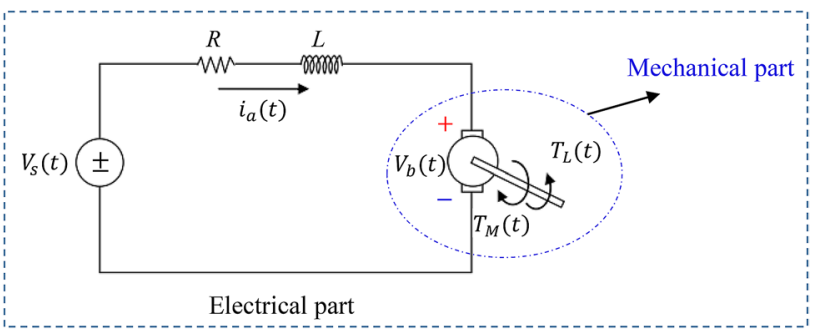

Fig. 2 Electro-mechanical structure of a DC motor where $k_{i} i_{a}(t)$ represents the output generated torque $\left(T_{L}\right.$ $(\mathrm{t}))$, and $k_{d} \frac{d \theta}{d t}$ is angular velocity dependent function or damping of the motor, which is shown by $T_{M}$ in Fig. 2. $T_{M}$ is proportional to the armature current. The parameters of Eqs. (1) and (2) are defined in Table 1.

For cases with no energy losses, it is assumed that $k_{d}=k_{v}$. However, in real practice with energy losses, the following ratio is approximated by $k_{d} \approx 0.65 k_{v}$.

Equations (3) and (4) can be re-arranged as follows:

$\frac{d^{2} \theta}{d t^{2}}+k_{d} \frac{d \theta}{d t}=k_{i} i_{a}(t)$

$L \frac{d i_{a}(t)}{d t}+R i_{a}(t)=V_{s}(t)-+V_{b}(t)$

Therefore, the mathematical model of Eqs. (3) and (4) can be expressed in terms of the transfer function or Laplace variable $s$ :

$s(J S+b) \theta(s)=K l(s)$

$(L s+R) /(s)=V(s)-K s \theta(s)$

By eliminating I(s) between Eqs. (5) and (6), the following equation can be derived, where the angular velocity is considered the output and the armature voltage is considered the input.

$P(s)=\frac{\theta(\dot{s})}{V(s)}=\frac{K}{(J s+b)(L s+R)+K^{2}}$

The transformed block diagram of the system is presented in Fig. 3. The figure shows how the parameters of the system interact among microcontroller, DC motor, and wiper, which are affected by environmental conditions via sensors. The motor is controlled by the angular velocity of the wiper, and it is perturbed by the magnitude of the

Table 1 Descriptions of the parameters used in Eqs. 3 and 4

\begin{tabular}{ll}
\hline Parameters & Description \\
\hline$i_{a}(t)$ & Current in the motor (amp) \\
$J$ & Moment of inertia of the motor \\
$k_{d}$ & Back-EMF constant (the rotational speed of \\
& motor's unloaded (RPM) to the peak voltage) \\
$k_{i}$ & Torque constant \\
$L$ & Motor inductance \\
$R$ & Motor armature resistance \\
$V_{b}(t)$ & Back-EMF voltage \\
$V_{s}(t)$ & Applied voltage to the motor \\
$d \theta / d t$ & Angular velocity of the motor shaft $(\mathrm{rad} / \mathrm{s})$ \\
$d^{2} \theta / d t^{2}$ & Angular acceleration of the motor $\mathrm{shaft}\left(\mathrm{rad} / \mathrm{s}^{2}\right)$
\end{tabular}




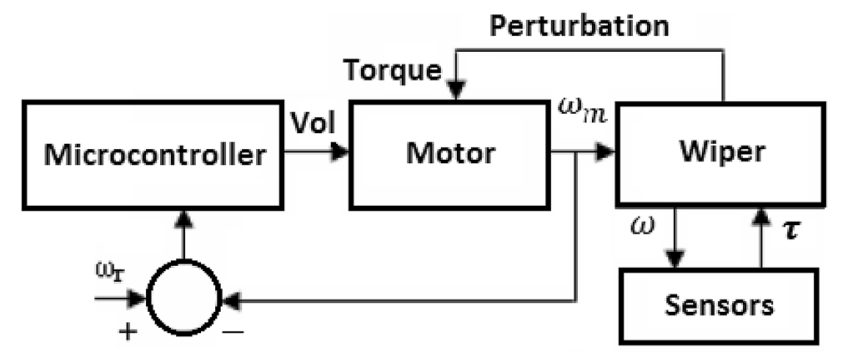

Fig. 3 Transform block diagram of the automatic cleaning system of the street light wiper's torque. The maximum torque is evaluated based on the dynamic model of the system or external forces, such as friction force and the weight of the handle of the wiper. To minimize a steady state error of the model, a proportional integer controller was used.

According to the derived equations and defining the inputs and outputs, the program can be controlled based on the flowchart shown in Fig. 4. It is seen that the proposed system can be controlled in two desirable conditions: automatically and manually. In automatic mode, two sensors were used as the decision variable for the system, including dust and rain sensors. For instance, once the water sensor senses the dust or drops of rain, the input voltage is applied. It is seen in the mechanism that the motor is the only actuator, which is controlled
Fig. 4 Logical expression of Arduino system to control the FACS of the street light

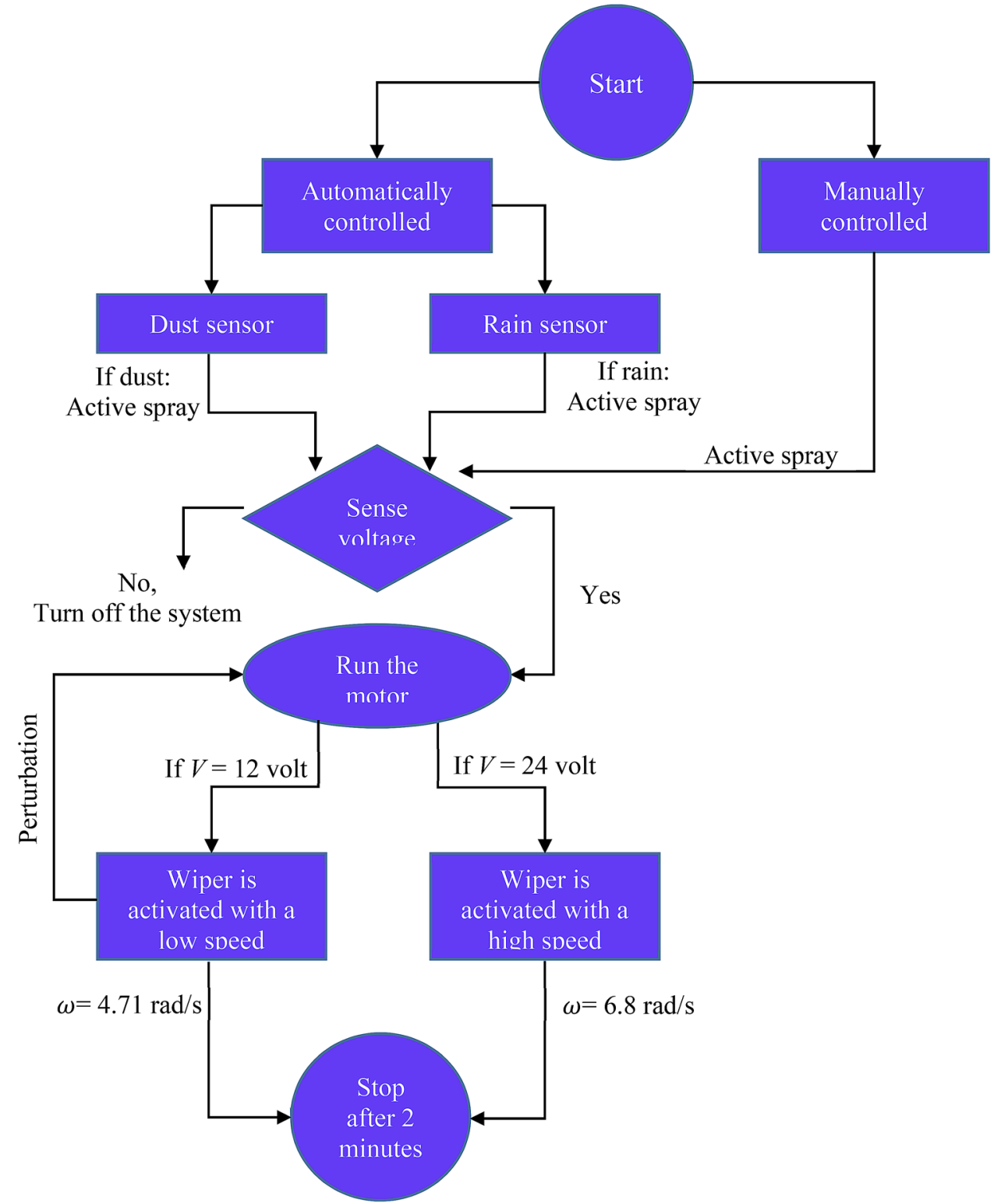


Fig. 5 A photo of the street light including cleaning system; a with a cove, $\mathbf{b}$ without cover

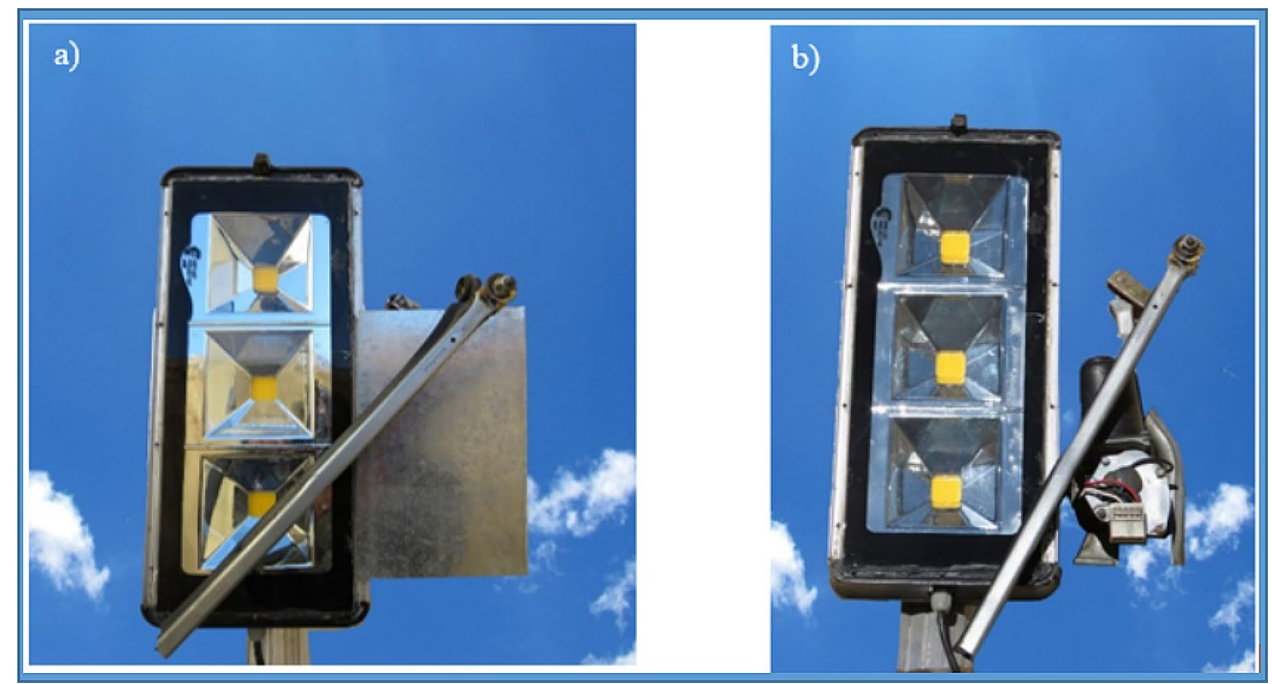

Fig. 6 A 3D model of street light including the pole, headlight, and other components of FACS

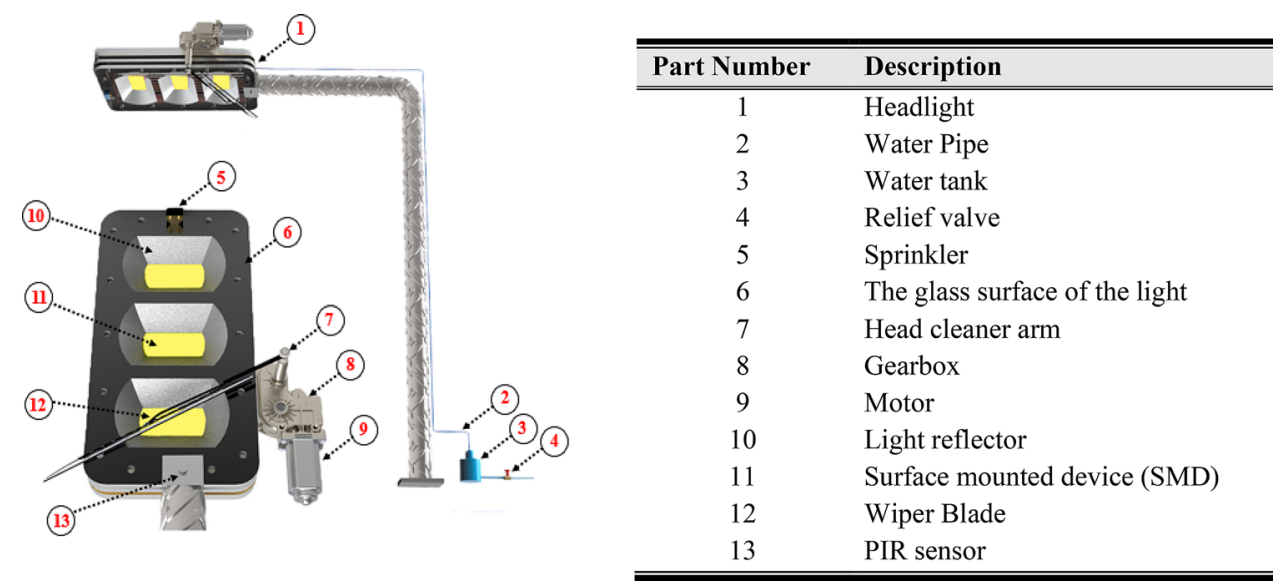

and perturbed with the torque. The evaluation is according to the dynamic model of the mechanism on which acts the essential outside forces. Therefore, the motor is automatically run after sensing the input voltage. Then, the mechanism of the wiper can be activated at two predefined angular velocities, depends on the magnitude of the input voltage. Finally, the motor will stop after cleaning the surface of the light, which has been defined in $2 \mathrm{~min}$. It is important noting that the proposed control system can be stopped manually for regular services or maintenance.

\section{Details of the mechanism}

A new design of the proposed system was manufactured and installed in Kermanshah city in Iran. The manufactured mechanism is shown in Fig. 5, which was mounted on a LED headlight, and the details of the system, including 13 components, are shown in a 3D schematic model in Fig. 6.
Table 2 Description of the components of the FACS mounted on a street light and associated with Fig. 6

\begin{tabular}{ll}
\hline Part number & Description \\
\hline 1 & Headlight \\
2 & Water pipe \\
3 & Water tank \\
4 & Relief valve \\
5 & Sprinkler \\
6 & The glass surface of the light \\
7 & Head cleaner arm \\
8 & Gearbox \\
9 & Motor \\
10 & Light reflector \\
11 & Surface mounted device (SMD) \\
12 & Wiper blade \\
13 & PIR sensor \\
\hline
\end{tabular}


The description of the components of the system is presented in Table 2.

The power consumption of the system can be easily evaluated based on the speeds of the motor at different conditions/voltages (e.g., 12-24 V) based on Table 3. For instance, the required current by motor and washer pump for low and high speeds are 7.5 A and 0.72 A. For the best efficiency, which is approximately about $40 \%$, the current is $3.2(\mathrm{Amp})$ and the speed of the motor is $36 \mathrm{rpm}$. The technical data of the motor is shown in Table 3.
FACS consists of two central units: (1) mechanical components, and (2) electrical units. The description and technical information of each unit are shown in Table 4 in detail, including the cost of each. Also, the total cost of units is presented in this table. As compared with the previous version of the cleaning system of the authors (e.g., AWS) [1] with 95.00 (USD), it is seen that less electrical components are used in FACS. Accordingly the cost of the electrical elements $50 \%$ is reduced. This leads to $30 \%$ cheaper total cost of FACS, as compared with AWS.
Table 3 Technical data of Gearmotor for windshield wipers MRT62-43 at two speeds 30 and 40 (RPM)

\begin{tabular}{llllllll}
\hline Technical data & Voltage & Current & Pin & Torque & Speed & Pout & Efficiency \\
\hline State & V & A & W & N m & RPM & W & $\%$ \\
\hline Speed max & 12 & 0.72 & 8.5 & 0.04 & 45.1 & 0.20 & $<3$ \\
Eff max & 12 & 3.20 & 38.3 & 4.00 & 35.7 & 15.22 & $35-40$ \\
Pout max & 12 & 7.50 & 90.3 & 10.50 & 23.6 & 26.08 & $25-30$ \\
Torque (max) 18-22 Nm & 12 & 15.50 & 185.5 & 22.00 & 0.0 & 0.00 & 0.0 \\
Reduction ratio & $1: 60$ or 1:68 & - & - & - & - & - & - \\
Protection class & IP44 & - & - & - & - & - & - \\
\hline
\end{tabular}

Table 4 Mechanical and electrical components of the FACS, including technical information and total cost of the system

\begin{tabular}{|c|c|c|c|}
\hline Components & Description & Features and technical information & Cost \\
\hline \multirow[t]{8}{*}{ Mechanical components } & Windshield wiper motor & $\begin{array}{l}\text { Extremely low noise ( } 45-55 \mathrm{~dB}) \\
12-24 \text { V D.C. supply } \\
\text { Output: } 20-30 \text { Watt } \\
\text { Two speeds (high speed: } 45 \pm 5 \mathrm{rpm} \text {, low speed: } 30 \pm 5 \text { ) } \\
\text { Output shaft made of stainless steel } \\
\text { Suitable for panel thickness from } 3 \text { to } 13 \mathrm{~mm} \text { (short shaft ver- } \\
\text { sion), or from } 3 \text { to } 38 \mathrm{~mm} \text { (long shaft version) } \\
\text { Stall torque: } 18-22 \mathrm{Nm} \\
\text { Protection class: IP44 } \\
\text { Rotate direction: CW and CCW } \\
\text { Reduction Ratio: } 1: 20 ; 1: 24 ; 1: 60 ; 1: 68 ; 1: 75 \text { (Customized) }\end{array}$ & USD 32.00 \\
\hline & Water pump (12 V-DC) & $\mathrm{Q}=150-200 \mathrm{~L} / \mathrm{h}$ & \\
\hline & Wiper pyramids & Stainless steel, Max arm length: (610 mm) & \\
\hline & Wiper blade & Water Repelling Coating-Rain-X water repelling & \\
\hline & Relief valve & $1 / 2$ inch, Pressure resistance 20 bar & \\
\hline & Water sprinkler & External diameter $=12 \mathrm{~mm}$, Internal diameter $=8.4 \mathrm{~mm}$ & \\
\hline & Water tank & $2-5 \mathrm{~L}$ & \\
\hline & Pipes & $12 \mathrm{~mm}^{2}$ & \\
\hline
\end{tabular}

Electrical components ATmega8 microcontroller Board

Fuse

Power supply

Writing circuit

Channel relay module with Opt coupler
High-performance

USD 33.00

PCB size: $200 \times 220$ mm, ICE ATmega8, 3 Relay, Rain Sensor,

Dust Sensor, PIR Sensor, and other circuit components

10 Amp

DL-30 W900-MP, 50/60 Hz, IP 67

$2 \times 2.5 \mathrm{~mm}^{2}$

High current relay, AC250V 10A, DC30V 10 A

2 LEDs to indicate when relays are on

Works with logic level signals from $3.3 \mathrm{~V}$ or $5 \mathrm{~V}$ devices 
Table 5 Comparison of the expenses of the mechanical and electrical elements of two automatic cleaning systems of street lights, including AWS and FACS

\begin{tabular}{llll}
\hline $\begin{array}{l}\text { Automatic cleaning } \\
\text { systems }\end{array}$ & Components & Costs $^{\mathrm{a}}$ & $\begin{array}{l}\text { Total } \\
\text { cost } \\
\text { (USD) }\end{array}$ \\
\hline AWS [1] & $\begin{array}{l}\text { Mechanical components } \\
\text { Electrical components }\end{array}$ & 66.00 & 98 \\
FACS (present study) & $\begin{array}{l}\text { Mechanical components } \\
\text { Electrical components }\end{array}$ & 33.00 & 65 \\
& El.00 & \\
\hline
\end{tabular}

${ }^{a}$ The cost are evaluated based on the expenses in 2018 for both systems in USD

The comparison of the mechanical and electrical units is presented in Table 5.

\subsection{Control circuit of FACS}

This section explains the technical control circuit of FACS comprising the washing system circuit of the headlights and turns on/off the circuit of the light employing Proteus software. Proteus is a user-friendly operating system, which can be used for electronic design automation. The electronic elements of the circuit designed with Proteus and the block diagram of the components in 2D graphics mode are shown in Figs. 7 and 8.

In the control circuit, three relays of R1, R2, and R3 were used. R1 is responsible for controlling the motor of the cleaning system; relays R2 and R3 control the pump of FACS and power input, respectively. A 5 V DC power supplier was utilized to drive the relays. The output of each relay also has been set based on $24 \mathrm{~V} D C$ of the cleaning system, pump, and light. A passive infrared (PIR) sensor was used to turn on and off the light for commuters. The dust sensor is also responsible for recognizing dirt accumulation and surface deposition. Once the surface of the light becomes dirty, the recognition of the dirt can be conducted in two methods: (a) full automatic control system; using the sensors of rain and dust; (b) a desirable predefined schedule based on the conditions of the environment, which can be set by the operator. In the first method, the mechanism automatically starts to clean the surface of the lights once a command transfers to the motor via the sensor. While in the former method, the duration of cleaning is set by a timer switch. This operation can be conducted automatically by an Alf and Vegard's RISC processor (AVR) control board (ATmega8). A water pump was

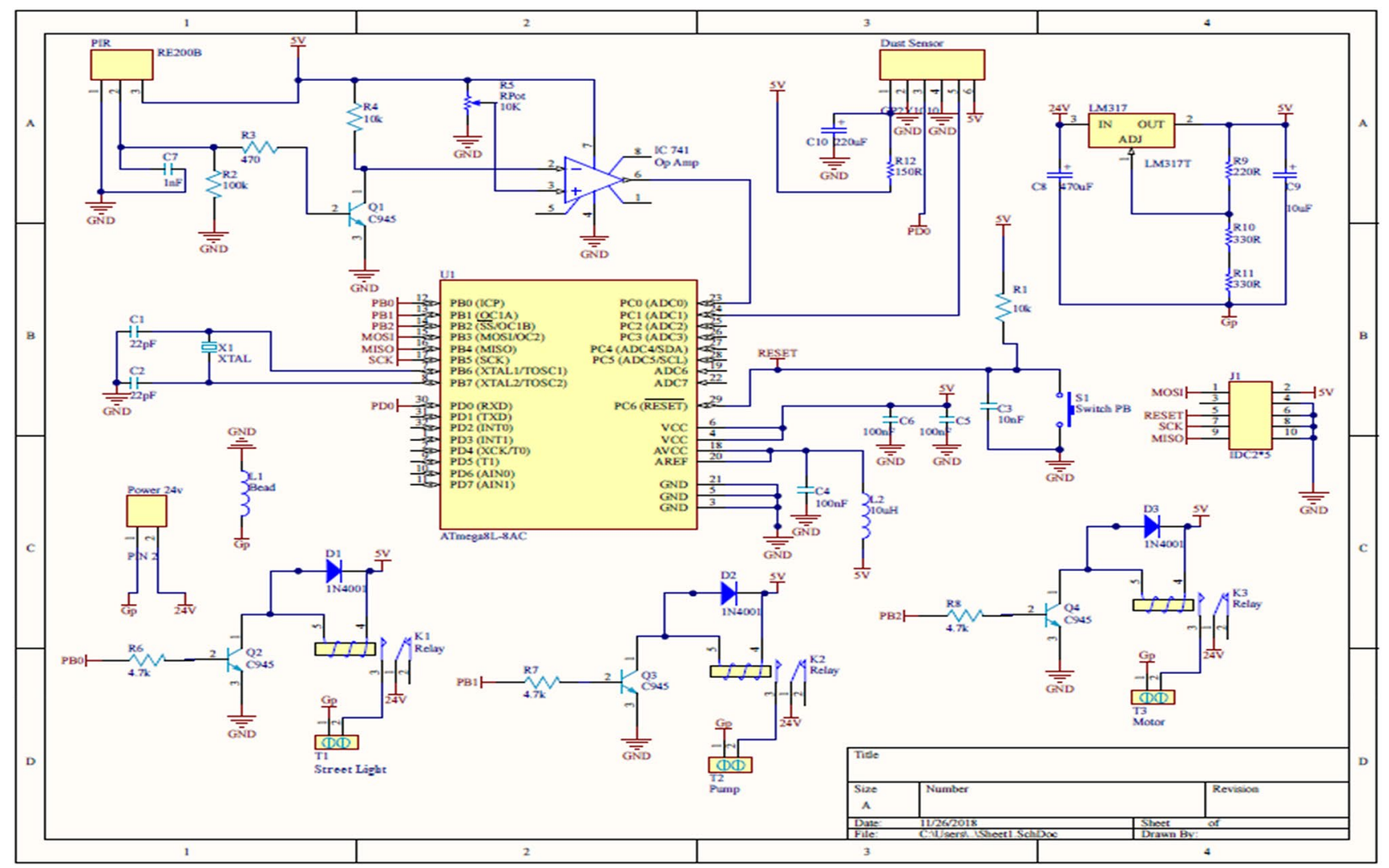

Fig. 7 2D graphics mode of the control circuit system, including washing system circuit of the headlight and turn on/off the circuit of the street light 


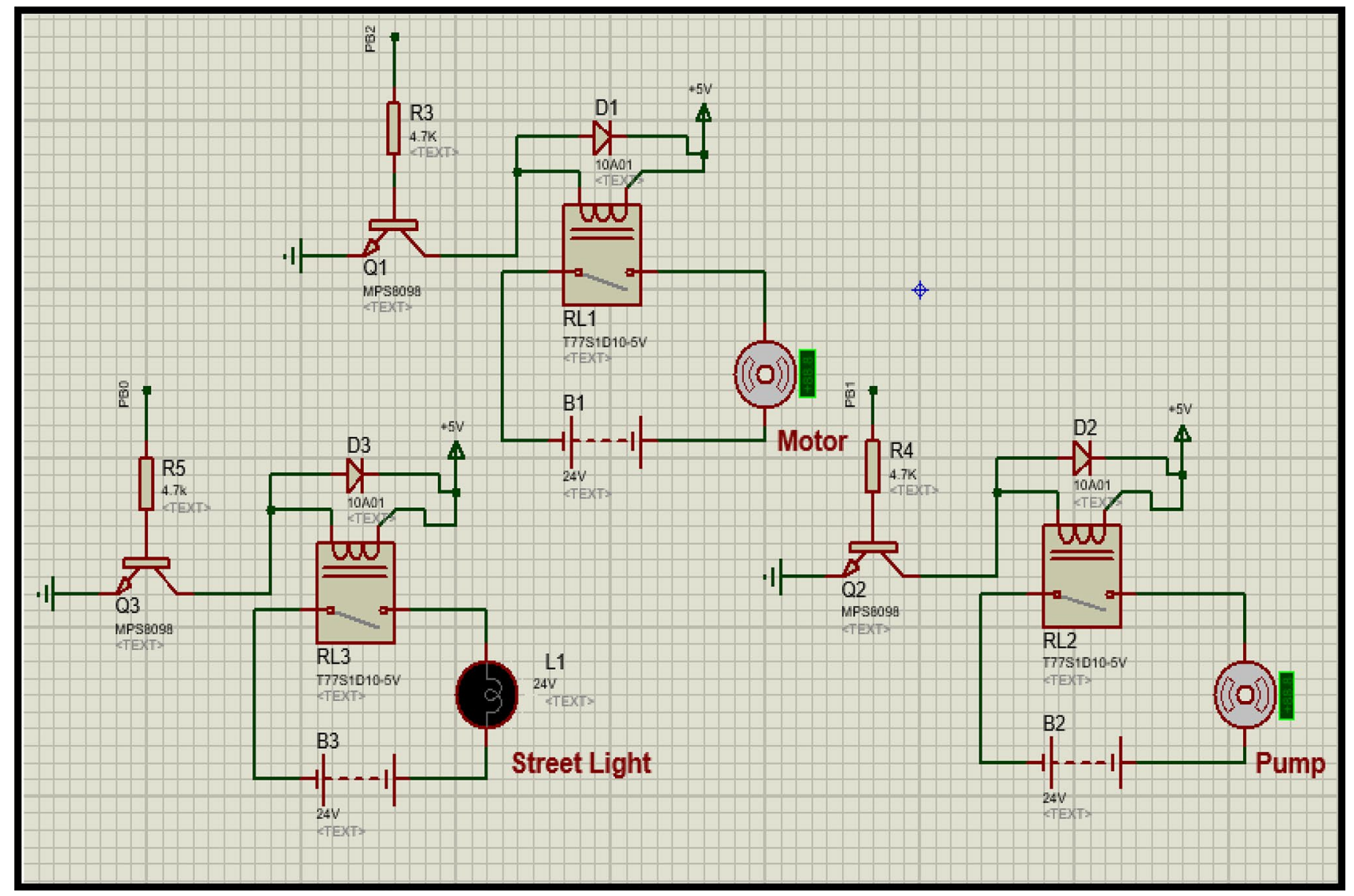

Fig. 8 Proteus schematic of washing system circuit of the headlight

used to facilities the cleaning processes even with dried dirt accumulation. Once the water is sprayed on the surface of the light, the wiper cleans the light's surface simultaneously. The speed of the wiper is adjustable based on the condition of the environment. It is also important to note that in addition to the water tank, FACS can be connected to the urban water system.

The light itself will be turned on or turned off based on the movements of the commuters or vehicles at a desirable distance using AVR control board (ATmega8). In addition to the above merits, FACS can be controlled by the following control systems: (1) Timer switch, (2) Global System for Mobile (GSM) Network, (3) GSM 900, 900A, 808 or General Packet Radio Service (GPRS) or GPS or SMS, (4) AVR using ATmega8, ATmega16, and ATmega32, (5) Manually, (6) PLC or using other control boards of loT.

Figure 8 shows the details of the connections of the relays and microcontroller in the control circuit using Proteus software. The ATmega8 microcontroller was used in the control circuit due to its commanding instruction, allowing it to provide many features in lesser pins. Figure 8 also shows the washing system of the surface of the light and describes the circuit of the motor and water pump system. It is shown that R1 is connected to the motor, which drives the cleaning wiper. R2 and R3 are connected to the water pump and turn on/off switch to run the pump and turn on/off the light, respectively.

As compared with the previous design of cleaning system [1], which derived by the loT technology, in the new proposed system (FACS), the ATmega8 microcontroller was used to reduce the expense of the system on the one hand and provide a fully automatic application. The proposed system can be also programmed by the operator and connected to different control boards, such as SIM800, SIM800A, SIM900, SIM900A, and other control boards that are based on the IoT if required. Therefore, FACS is independent of the internet service, and the commands can be automatically transferred via sensors to run both cleaning systems and turn on/off the lights depends on the presence of the commuters or vehicles. Consequently, in case of no net service in some areas, FACS can be run without trouble. It is worth noting that in case of employing FACS in severe cold weather, (below $0{ }^{\circ} \mathrm{C}$ ), the water pipe lines and water tank should be protected from freezing.

The printed circuit board (PCB) of FACS was designed, and the circuit board drew for printing in Altium Designer 


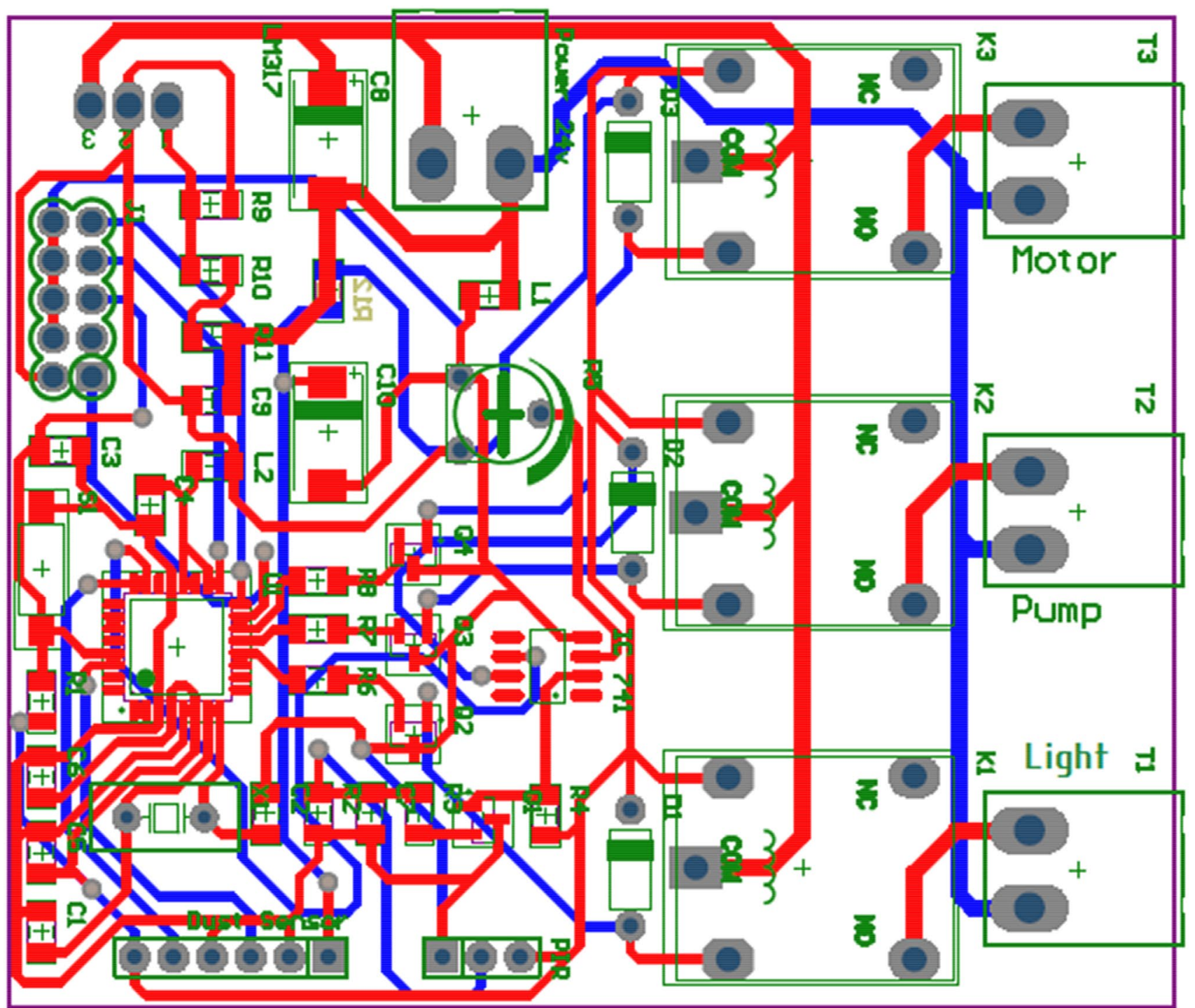

Fig. 9 PCB circuit control system of FACS using AVR (ATmega8 IC) microcontroller

software, as shown in Fig. 9. Altium Designer software, with several benefits, combines many features and functionality, which can provide a consistent board with a complex layout. A fully automatic washing system of the light was designed and considered in this circuit. The circuit also covers an automatic turn on/off the light according to the motion of commuters. The whole electronic components were installed on the PCB board, as shown in Fig. 10.

A better comparison among the available systems can be achieved by summarizing the features of each method, as shown in Table 6. The table compares the required operator, the amount of water, and the required time for cleaning of the light for each method.

Among the available cleaning systems, using a proper full automatic washing system with a remote control system appears to be more suitable and cost-effective rather than other methods (methods 1-3). Recently, Hadipour et al. [1] designed and used AWS to overcome the weakness of the conventional methods for cleaning the LED street lights, which operated via the internet of things (loT) technology (Fig. 1d). While AWS reduced the human operation and eliminated the traffic congestion problems, it required to replace the cleaner's head (wiper) when necessary due to the effects of the sun and rain. In the new proposed system known as FACS, it was attempted to overcome the previous issues associated with AWS. Therefore, a robust mechanism was designed and manufactured with lower costs. All these imply that FACS can be introduced and employed as a suitable mechanism for washing the street lights. 


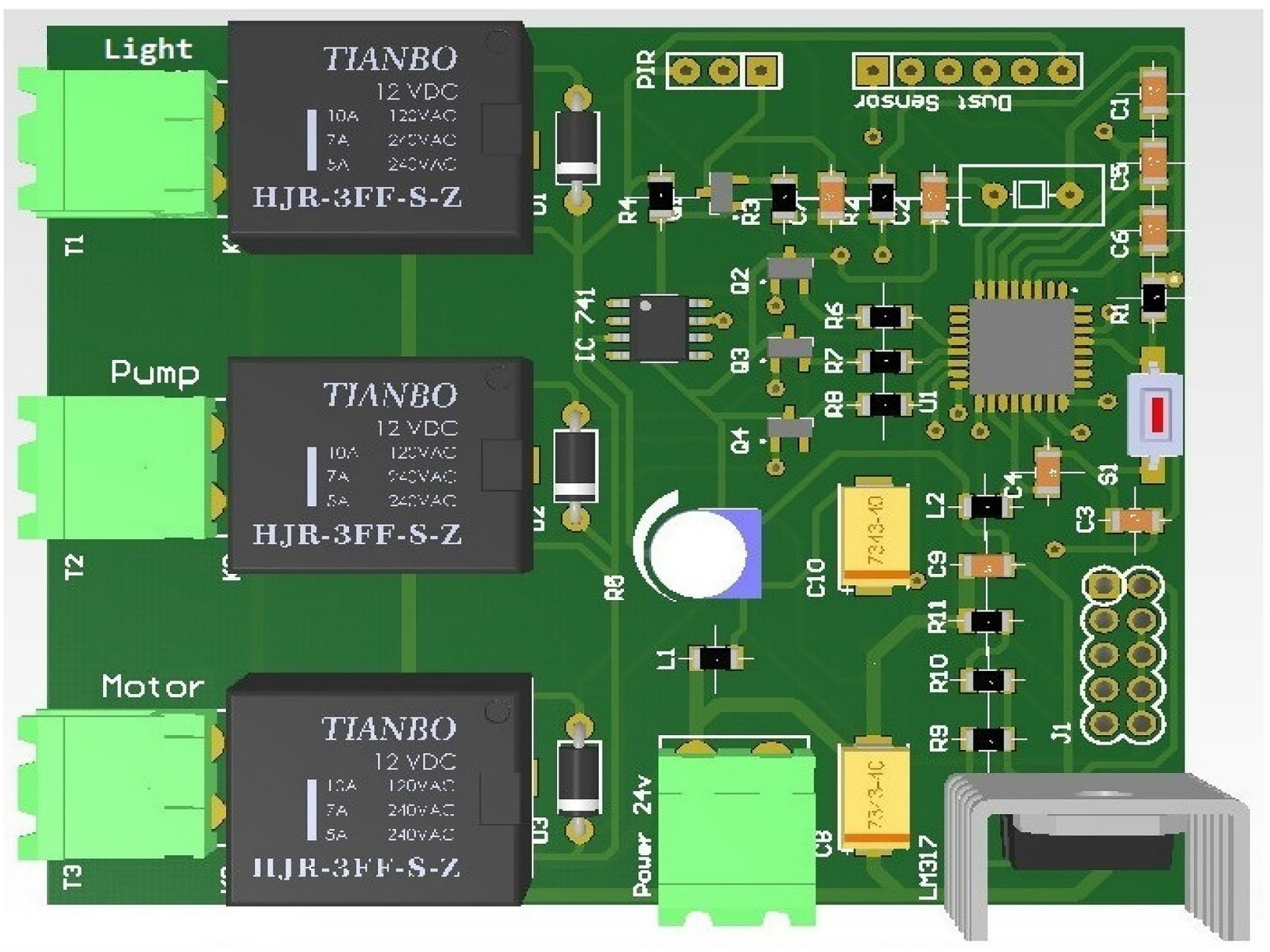

Fig. 10 The Mainboard of FACS including installed electronic components using AVR (IC ATmega8) microcontroller

Table 6 Comparison of the features and requirement of each cleaning system for the surface of the street lights

\begin{tabular}{lllll}
\hline No & Cleaning systems & $\begin{array}{l}\text { Required operator } \\
\text { (person) }\end{array}$ & $\begin{array}{l}\text { Consumed } \\
\text { water (I) }\end{array}$ & $\begin{array}{l}\text { Required } \\
\text { time } \\
\text { (min) }\end{array}$ \\
\hline 1 & Industrial lifts & $2-3$ & $1-1.5$ & $6-10$ \\
2 & Climbing robot & 2 & $0.5-1$ & $10-30$ \\
3 & Folding lamp post & $1-2$ & 0.5 & $5-10$ \\
4 & Automatic washing system (AWS) & 0 & $0.2-0.5$ & 1 \\
5 & Full automatic cleaning system (FACS) & 0 & $0.2-0.3$ & 1 \\
\hline
\end{tabular}

\section{Conclusions}

In this study, a new robust washing system of the street lights was designed and manufactured, known as a fully automatic cleaning system (FACS). An extensive comparison of the available cleaning systems is performed, focusing on the existing technologies, pros and cons, operation, and maintenance to clean the surface of the street lights. It is shown that as compared with conventional technologies, the fully automatic system can overcome the weaknesses associated with conventional methods, such as operators, operation time, traffic congestions and water/or energy usage. While the lifetime of the wipers is dependent on environmental factors, such as the sunlight and temperature, FACS is a very promising mechanism with its advantages. The new proposed system is more robust than AWS with approximately $30 \%$ 
lower cost. FACS not only can be connected to the urban water system but also is connectable to a separate water tank. It should be considered that during severe cold weather, the water pipe lines and water tank are at risk of freezing and they should be protected. The system can be controlled via loT and can be installed on most types of street lights. While AWS was only installed on LED lights, FACS can be installed on the most type of street lights. The operation time is quick; consequently, it cleans the surface of the light in a shorter time as compared with AWS, which causes a lower cost in maintenance. By cleaning the accumulation and reducing the temperature of the light, FACS increases the light life. The proposed system is an intelligent mechanism and can be programmed by the operator and connected to different control boards, such as SIM800, SIM800A, SIM900, SIM900A, and other control boards that are based on the IoT; however, the application of FACS is limited for those areas without net services. In this condition, further development of the FACS will better enhance the application of the system by employing an electronic timer switch.

Acknowledgements The contribution of Mr. Mohsen Aghazadeh Shiran for preparing some information and collected data is gratefully acknowledged.

\section{Compliance with ethical standards}

Conflict of interest The authors declare that they have no conflict of interest.

\section{References}

1. Hadipour M, Derakhshandeh JF, Aghazadeh Shiran M, Rezaei $\mathrm{R}$ (2018) Automatic washing system of LED street lighting via internet of things. J Internet Things 1-2:74-80

2. Enerdata (2017) Global Energy Statistical Yearbook 2018. https ://yearbook.enerdata.net/electricity/electricity-domestic-consu mption-data.html. Accessed 2 Oct 2018

3. Mekhilef S, Saidur R, Safari A (2011) A review on solar energy use in industries. Renew Suistain Energy Rev Elsevier 15:1777-1790

4. Esen M, Yuksel T (2013) Experimental evaluation of using various renewable energy sources for heating a greenhouse. Energy Build Elsevier 65:340-351

5. Nelson VC (2013) Wind energy: renewable energy and the environment. CRC Press, Taylor and Francis Group, Boca Raton

6. McCarthy JM, Watkins S, Deivasigamani A, John SJ (2016) Fluttering energy harvesters in the wind: a review. J Sound Vib 361:355-377

7. Bernitsas MM, Raghavan K, Ben-Simon Y, Garcia E (2008) VIVACE (vortex induced vibration aquatic clean energy): a new concept in generation of clean and renewable energy from fluid flow. J Offshore Mech Arct Eng 130:1-15
8. Derakhshandeh JF, Gharib N, Hadipour M (2019) An intelligent loT-based control system for harnessing hydropower energy from wake induced vibration. J Ind Electron Appl 3(1):2

9. Derakhshandeh JF, Alam MM (2019) A review of bluff body wakes. J. Ocean Eng 182:475-488

10. Demirbas A (2008) importance of biomass energy source for Turkey. Energy Policy Elsevier 36:834-842

11. Liu S, Abrahamson LP, Scott GM (2012) Biorefinery: ensuring biomass as a sustainable renewable source of chemicals, materials, and energy. Biomass Bioenergy Elsevier 39:1-4

12. Berg N (2012) The street energy drain on cities: streetlights. https ://www.citylab.com/solutions/2012/04/secret-energy-drain -cities-streetlights/1856/

13. Sutandi AC, Pinem RDA (2017) The application of road lighting standard towards sustainable transportation in large cities in Indonesia. Procedia Eng 171:1463-1471

14. Ożadowicz A (2017) Energy saving in the street lighting control system - a new approach based on the EN-15232 standard. J Energy Effic 10(3):563-576

15. Eskandari N, Jamshidieini B, Rafiei M, Abooei E (2017) Maintenance of street lights by climbing robots in Alborz electric power distribution company. In: Proceedings of 24th international conference on electricity distribution glasgow

16. Noohi E, Mahdavi SS, Baghani A, Ahmadabadi MN (2010) Wheel-based climbing robot: Modeling and control. Adv Robot 24(8-9):1313-1343

17. Bayindir R, Cetinceviz Y (2011) A water pumping control system with a programmable logic controller (PLC) and industrial wireless modules for industrial plants-An experimental setup. ISA Trans 50:321-328. https://doi.org/10.1016/j.isatra.10.006

18. Fadaei A, Salahshoor K (2008) Design and implementation of a new fuzzy PID controller for networked control systems. ISA Trans 47:351-361

19. Amin S, Litrico X, Sastry S, Bayen A (2012) Cyber security of water SCADA systems: II attack detection using an enhanced hydrodynamic model. IEEE Trans Control Syst Technol. https:// doi.org/10.1109/tcst.2012.2211874

20. Amin S, Litrico X, Sastry S, Bayen A (2013) Cyber security of water SCADA systems-part I: analysis and experimentation of stealthy deception attacks. IEEE Trans Control Syst Technol 21(5):1963-1970

21. Durrani S, Arif H, Ehtisham A, Asad A, Khan S, Hazrat A (2018) A smart framework for power distribution and load balancing using Arduino. In: Proceedings of the 1 st international conference on power, energy and smart grid (ICPESG). https://doi. org/10.1109/ICPESG.2018.8384515

22. Gupta RA, Chow M (2010) Networked control system: overview and research trends. IEEE Trans Ind Electron 57(7):2527-2535

23. Klemenjak C, Egarter D, Elmenreich W (2016) YoMo, the Arduino-based smart metering board. Comput Sci-Res Dev 31(1-2):97-103

24. Hadipour M, Derakhshandeh JF, Shiran MA (2020) An experimental setup of multi-intelligent control system (MICS) of water management using the internet of things (IoT). ISA Trans 96:309-326

Publisher's Note Springer Nature remains neutral with regard to jurisdictional claims in published maps and institutional affiliations. 